\title{
Contemporary Reflections on Hysterical and Obsessive Neurosis
}

\author{
Henrique Guilherme Scatolin \\ PUC-SP (Pontificate Catholic University of São Paulo), São Paulo, Brazil
}

\begin{abstract}
This paper aims to perform a contemporary reflection on the two classical neuroses studied by Freud: the hysterical and the obsessive. From a review in the Freudian work, the author proposes the articulations of this neuroses with the contemporary manifestations, emphasizing how the desire and the impulsive manifestations become the propelling spring of these psychopathologies. This paper is divided into two parts: The first is related to female hysteria to the Oedipal movements articulated to the castration complex that provide the output to the girl desires; and the second correlates the anal-sadistic phase with the obsessive symptomatic movements, highlighting the symptomatic positivity in this neurosis. It is concluded that, while the hysterical neurosis puts in evidence the phallic fixation, moving the hysteria in favor of the phallic bright manifestation and the social recognition in its productions, the obsessional neurosis proposes the freezing logic of thoughts and actions, denoting that these manifestations bring, to the foreground, the characteristics of the self-destructive impulse present in its etiology.
\end{abstract}

Keywords: penis envy, positivity, anal-sadistic and phallic fixation

\section{Hysteria: A Brief Articulation on the Contemporary Symptomatic Manifestations in the Brazilian Context}

Among the classes of neurosis studied by Sigmund Freud, the conversion hysteria can be considered the hysterical neurosis itself. This neurosis is side by side to the obsessional neurosis and the anxiety hysteria - the phobia — which wealth was "hushed up" by the famous Panic Syndrome.

Among these three classes of neurosis - the obsessive, phobic and hysterical, the conversion hysteria was the precursor to the psychoanalysis origin. In his early studies, Freud did not use the "conversion" hysteria terminology, since the "conversion" terminology was considered as a hysteria itself. In this conversion, the psychic impulse, interlaced to the desire, is bodily manifested through contractions, blindness, and other symptoms, but it was on the analysis of a phobia case - the little Hans - that the father of psychoanalysis began to discern between the anguish hysteria (with all its clinical richness that the famous psychiatry confined it) and the conversion hysteria.

In the thresholds of this historical trajectory, between the pre-psychoanalysis and the analysis of little Hans, the conversion hysteria and its clinical manifestations were never relegated to a second plan. In this historic meander, the historian Roudinesco and Plon (1988) point out that, between 1880 and 1900, the world was going through a real epidemic of hysterical symptoms, being these understood by doctors, historians, and writers as the convulsive signs of female nature as a result of the industrial society consequence in the 19th century.

This time Jean Martin Charcot is highlighted, a French physician and neurologist, who understood the hysteria as a functional and hereditary disease, which affected men and women. Through the hypnosis, he tried

Henrique Guilherme Scatolin, Master, PUC-SP (Pontificate Catholic University of São Paulo). 
to demonstrate his assumptions on this pathology.

This technique was widely used with his patients of Salpêtrière, inducing to his hysterical symptoms. This doctor, to whom Freud had a huge consideration, directly influenced the psychoanalysis father understandings on hysteria. Between 1888 and 1893, Freud brings from Charcot the idea in which the hysterical neurosis is a result of a childhood trauma, reporting that he would have its sexual causes and would be the result of a sexual abuse really lived by the child during his childhood.

Due to his self-analysis in 1897 , he waives this theory and emphasizes the role of fantasy in the hysteria etiology. In the passage to the 20th century, the psychoanalysis technique suffers a new change: Freud abandons the cathartic method of Breuer-a method which psychoanalytic therapy was based on the treatments carried out by hypnosis. In this method, through hypnosis, the patient came into contact with the traumatic events, releasing the emotions related to him.

In contrast, Freud adopts the free association, focusing the verbalized material freely throughout the sessions. This method, according to Laplanche and Pontalis (2001), would insist in indiscriminately expressing the thoughts freely from the childhood memories, reports of dreams, and the symptoms brought by the patient.

At the turn of the century, in 1900, Freud writes The Dreams Interpretation, the book which is considered as the landmark of the beginning of psychoanalysis. In this context, hysteria was understood as a psychic conflict and no longer as a result of a traumatic event. The hypnosis had been abandoned and the free association method gains its space.

Before proceeding, the author would like to highlight that, although 114 years have passed from the hypnosis technique abandonment, this, in the Brazilian current society, gains space between charlatan "professionals", which use it in favor of their primitive religious rituals. We are no longer in Salpêtrière and the hysterics are no longer put on stage; but the stage was transformed into the television and the internet, which gives room for the collective alienation that moves a mass in the search of an answer to the others suffering. A reply in the search for nothing, moved by the desire; such as the primitives that beat their drums in the search for an answer from their loved superior for the pain of their soul. Therefore, we observe the suffering of a mass in which many, by the scientific ignorance, put, often, the salvation in people who they shamelessly use, and without the ethical pillar, the distortions of hypnosis technique to justify the failures and the diseases of this crowd, evoking the evil beings within these people. So we return to middle ages, because all that is wrong is not our fault, but the punishments of superior beings that we should exorcise.

In this meander, hysteria never was made so clamored in our society. But before proceeding, the author would like to point out that we cannot equate hysteria to madness, like many still do, repeating the mistakes of our past. It is heard by the author many saying that the hysteric is a crazy woman that screams, kicks and shows up. But it is not. On the contrary, if the show occurs, this is of her own desire that circulates and moves the dissatisfaction of her own psychism. So if hysteria puts in evidence the desire and we owe them the psychoanalysis origin, we will return to Freud, specifically until 1901, when Freud wrote the classic case of hysteria: the Dora case.

In this clinical case, he considered hysteric "any person in which an opportunity of sexual excitement provokes... a sensation of disgust, whether that person presents or not somatic symptoms" (Freud, 1905, p. 50). However, it was after the studies on infant sexuality that Freud indicated the core of hysterical neurosis: This would be in the impossibility to liquidate the Oedipus complex (nuclear complex of the psychic subject constitution). Such statement requires a better explanation. 
All of us, human beings, entered in the Oedipus complex, but how each one dealt with the destinations of this complex, only an analysis can point out. In this meander, according to the Freudian theory, the female Oedipus complex does not occur similar to the male, since in the female path of this complex, the penis envy comes to perform a key role. In this case, the girl enters this complex by the discovery that not all feature a male organ. In this turmoil, she disconnects from the mother-since this deprived her from the male organ - In the search of her father, expressing the desire to have a son with him, which in the past she desired to have from her mother. Thus, all female Oedipus complex entire development is concrete in the penile envy shadow. However, it is the fear of the maternal love loss that throws the girl "out" of this complex, and the girl may show three possible escapes: the sexual inhibition or hysteria, the masculinity complex, and the femininity.

As the female hysteria is presented as possible it exists to the female Oedipus complex, it is the libidinal fixation in the phallic phase that will move it in its eternal complaints of dissatisfaction. In other words, among the three phases of psychosexual development described by Freud - the oral, anal, and phallic - the hysteria features a great part of the libidinal fixation in the phallic phase, a phase that culminates with the Oedipus complex. In contrast, if this phallic fixation was not enough, there is also a small fixation on oral phase, which justifies why many hysterical have such strong melancholic traits. Therefore, it was this world so rich and enigmatic of female universe that surprised Freud at each phase of his work.

However, the author points out that every hysterical will move according to these fixations, assuming, in each case, a unique position against its transference. So the psychotherapists are responsible for hearing them, always being attentive of their fantasies (and not the reality) in their verbalizations.

Those fantasies that launch new light on the manifestations of its libidinal fixations: each hysterical moves by the phallus (or its lack), leading her to claim prominent places and positions in society, putting in checkmate the male positions and jobs. This means that the hysterical complaint, which reflects this phallic position and that still moves many women, is very common when they assume roles and positions below the men. Such difference can never end, because it is this drives her desire, given the lack. And in the completeness pursuit of this lack, a fact that she can never show, the hysterical is capable of great facets, these being of great social recognition.

Here the author would like to point out a book called Everything in Pink, written by the own hands of the arts godmother of São Paulo, the great Yolanda Penteado. In his understanding, the author of this book Everything in Pink, at the same time that describes her own story, brings the issue of love of her childhood in relation to her parents, as well as the good identificatory relation with her mother, pointing to the life force that was present in her psychic constitution. When getting aware of her love frustrations and how she stood up in view of her personal conflicts, Yolanda portrays how love and seduction were part of her daily life. To compensate this lack of phallus, she lived directly with phallic men, such as Santos Dumont (to whom she refused numerous times the marriage invitation), but came to marry, after her divorce, with CiccilloMatarazzo, one of the Brazil's most influential men in the 50s. In the 1920 and 1930 decades, she was present in the female claims for the equal vote, since this was a right only of men. She was also present, with Anita Malfatti and Tarsila Amaral, in the Modern Art week, in the decade of 1920. Let us see: Influential women that made history; but her greatest wealth was the MASP (Art Museum of São Paulo) opened in the decade of 1950. Thus, her life was marked by works that brought the phallic glow to her person. A bright that was portrayed with plenty of life in the book mentioned above. 
Examples aside, the author would like to return to a point of hysteria: the body symptoms. Roudinesco and Plon (1998) point out that the originality of this neurosis lies in the fact that her unconscious psychic conflicts are expressed from a theatrical way through body symbolizations, such as the attacks or convulsion in epileptic appearance, paralysis, contractures, and other symptoms. Among these, a feature that catches the author's attention is the seduction, moved by the desire.

In hysteria, due to the phallic fixation, a triangulation is formed, where many serious hysterical are put as the third in the relationship. When they are called by the partner to assume a serious relationship, as a couple, such pleasure is lost. Consequently, the desire starts to move in search of relationships that refer again to this triangulation, decoding its identificatory problematic. There is a hysterical saying: "I was not born to be a woman; I was born to be a lover, the other, only that". Such relationships put in evidence the rivalry with the mother in the search of the father and that, in the adulthood, it is incorporated, respectively, by the lover and the lover wife. Therefore, the seduction becomes the main weapon, but falling in its claws is everything that the hysterical least wants, but desires. And in this psychic conflict, hysteria moves in the meanders of modern society.

Due to this, the popular judgments label them of numerous derogatory names, repeating the lack of knowledge about this pathology. If before, the hysteria was decoded as demonic possession, since the witches put in checkmate the male phallus and the religion phallus, currently, the hysteria acquires even more force, because the hysterical dispute the society hypocrites pillars through the pan protests in public square, but her demands for better wages, etc.. The inquisition of fires no longer exists, but they are burned in the inquisitions that exist within each one of us when we contest what cannot be contested: the female independence. That is why this neurosis will never be outdated.

\section{Contemporary Manifestations of Obsessional Neurosis: A Clinical Reflection}

Today we live in a society in which the famous psychiatric classifications are present even in the conversation circles among friends. In the coming and going of the day to day complaints, who never suspected that was experiencing depression or phobias? Within this macro context, there is a micro context that needs a special look: the clinic, the space in which the psychotherapist bends himself on the history of each patient, trying to understand them in the context where each one is inserted. In the meanders of these "modern pathologies" that move the intense and famous company of pharmaceuticals, it is still very common to hear from many patients, in the first sessions, that they suffer from the panic syndrome or that they are full of cleaning manias. Many associate this manias with the famous T.O.C., i.e., with the obsessive compulsive disorder.

This disorder, present in the psychiatry manuals as an anxiety disorder, was compared to the obsessional neurosis. Such comparison is a big mistake; since this compendium does not consider the uniqueness of Freudian discoveries made by the father of psychoanalysis at the turn of the 19th century until his last writings. This means that we cannot compare the obsessive compulsive disorder to the advances of the studies on obsessional neurosis, both Freud and also the post-Freudian, where we find the British psychoanalyst Melanie Klein and the French psychoanalyst Jacques Lacan. While the obsessional neurosis presents a plurality of clinical manifestations, considering the unique story of each patient, the obsessive compulsive disorder only focuses on the symptomatic manifestations.

Here a dilemma arises: The obsessive symptomatic manifestations of this disorder does not necessarily belong to the obsessional neurosis, since the differential diagnosis of psychotherapists of psychoanalytic 
approach support in the infant desires manifestations of these neurotic; that is, all and every obsessional neurosis diagnosis is based on the transfer of childhood complexes, where the anal impulses of infant sexuality keep its proper importance. While the psychotherapist observed and heard the history manifestations of each patient that underlies behind this neurosis, many psychiatrists still focus only on the obsessional symptomatic manifestations for their diagnosis, not considering the infant desires and the impulses that are spread behind these symptoms.

As we are inserted in a society where the American pragmatism still perpetuates, many psychologists (and other health professionals) still criticize the psychoanalytic psychotherapies, signaling that these are long and little effective. This criticism deserves reflections: If, on one hand we have this posture that refers us to the 19th century, on the other, this neurosis, which begins between six and eight years, deserves a resumption in Freudian work. In other words, if the obsessional neurosis is not the obsessive compulsive disorder, what would this neurosis be then? Let us resume briefly the Freudian studies.

\section{Freudian Conception}

The obsessional neurosis owes (and a lot) to Sigmund Freud studies, the psychoanalysis mentor. His early studies on this neurosis are dated 1894, when he wrote the text The Psychoneurosis of Defense, breaking with the classical psychiatry vision and demarcating, according to the psychoanalyst Hayat (2005), that this neurosis had as an origin a intrapsychic conflict of sexual origin that mobilized and blocked all the energies of the individual. Thus, since the end of the 19th century, next to the hysteria, the obsessions began to gain the look of Freud, once he noted that in the etiology of obsessions classic symptoms - such as the doubts, guilt, and rituals-There was a psychosexual component; in other words, a component of sexuality linked to the psychic.

After having written two books that put in check the Cartesian thinking of his time-The Dreams Interpretation (in 1900) and the Three Essays On the Infant Sexuality (in 1905)—Freud resumed the study on the obsessional neurosis in a short article titled Obsessive Acts and Religious Practices, published in 1907. In this, he compares the obsessive rituals to the devout acts, being the obsessive rituals moved by the individual desires of each neurotic. However, this context requires a special attention: Ten years before, in 1897, due to his self-analysis, Freud abandoned the traumatic theory of neuroses.

This theory understood that the obsessional neurosis would be the result of a sexual abuse not penetrated by a pervert adult in the childhood of these patients. Due to his self-analysis, the psychoanalysis father understood that the complaints that persisted behind the reports of these patients came from their fantasies and not from the reality experienced by them. It was in these fantasies (and not in reality) that the sexual content was present. So, Freud begins to observe the fantasies behind the neurotic symptomatology, leading him to abandon this theory. Later, Freud resumes the studies on obsessions in 1907, when writing the article Obsessive Acts and Religious Practices. In this meander, the psychoanalysis father was already analyzing the case of Ernst Lanzer, the famous clinical case that became known as the Rats Man.

Lanzer suffered from obsessions that rats could penetrate him by the anus. Such obsessions were triggered after hearing the Lieutenant of his army report of an oriental torture technique. In this technique, according to Oudinesco and Plon (1998), the prisoner was forced to undress and to kneel on the floor, and on his buttocks was fixed, by means of a belt, a large perforated bowl through which a rat was agitating. When trying to escape, this rat could penetrate into the rectum of the begged, inflicting him bloody wounds. 
This idea afflicted him so much that he himself sought Freud due to his ruminant and punitive thoughts with the rats. Therefore, because of these obsessions, this patient became known as the Rats Man, becoming the first classic case of obsessional neurosis in the history of psychoanalysis.

When publishing this case in 1909, Freud arouses the clinical attention for the entire obsessive symptomatology that translated the ambivalence between the love and hate of this patient. His obsessions reflected his anal impulses, from his childhood.

But it was in 1913, when writing The Inclination to Obsessional Neurosis, that Freud pointed out the relevance of the anal-sadistic phase and the anal eroticism for the understanding of the obsessive symptomatology. Let us remember that Freud described three phases of human psychosexual constitution: the oral phase (of external world incorporation through the mother milk suction), the anal-sadistic phase (where we find ambivalences surrounded by the faeces game), and the phallic phase (where culminates the Oedipus complex - the unconscious representation by which the amorous and hostile desires of children are expressed towards his parents).

Freud, in this text of 1913, stresses the importance of the anal sadistic phase for the understanding of obsessional neurosis symptomatology, since the regression of libido - of sexual energy - to this phase is the predisposition to understand the events that occur in this neurosis. Thus, we find in the anal-sadistic phase the pillars that guide the movements of these neurotic. But how can we identify them?

It is very common, in adulthood, that these neurotic present a supermorality, a super kindness, such as an inclination to order and harmony. Such features are defenses against the dirty, anal, impulses present in their unconscious. But between the meanders of clinic and the social, the obsessional neurosis brings something that is missing in the current Brazilian society: the inclination to order, hierarchy—given by the relationship with the father-and the issue of the work. This is the inheritance of the symptomatic positivity of this pathology, which many researchers cannot see. While many are dealing with the obsessive symptoms through a negative lens, creating pathologies for everything and everyone that show manias and rituals, the positivity of this neurosis brings features that break with these stereotypes. But which would they be?

Among the guilty, the rituals and the attachment to time and money-characteristics that refer, directly or indirectly, to the anal-sadistic phase - the obsessive neurotic makes the work of the springboard for the (dis)pleasure of his daily life, leading the secondary benefits of this "symptom" until the structuring of his daily life. So, these neurotic have the work, religion, and the family as the triad that regulates his behavior and his judgments.

If we analyze the history of each one in its uniqueness, even in their threshold, this neurosis reveals a richness of demonstrations that goes since the primitive thinking form - where we find the superstitions - up to the relationship with the father, being this a representative of the law that the obsessive incorporates and transmits throughout the generations. His ruminant, tragic or banal thoughts are evoked and softened over its rituals: In these, the father figure is always evoked by the guilt that drives these neurotic in their eternal beliefs, for example, once a patient reported me that if he did not hide the scissors of his house, his father could die. And in his prayers, he begged for his father constant protection. This excerpt demonstrates the ambivalence of this obsessive patient.

Among so many manifestations, the religious devotion is another trademark of these patients, driven by guilt. This fact had already been observed by Freud in 1907, in the text already mentioned, and numerous times reintegrated throughout his work, mainly in Totem and Taboo, published in 1913. 
In this text, when comparing the primitive minds with the mind of these neurotic, the psychoanalysis father had already highlighted the belief in the superstitions and in thought power can be highlighted in this pathology. As the Rats Man had already been analyzed in 1909, Freud reiterates that in this neurosis, the regression of acting for thinking was evident. In other words, the great (dis)pleasure is in rumination of thoughts that symbolically evidence the desires of these patients. The thought comes to replace the act itself, leaving them given to inaction, i.e., the lack of attitude due to the ambivalent conflict in his psyche. For this reason, these patients spend hours and hours ruminating tragic thoughts of death of a loved one who, many times, refers to the old parricide desires of his own childhood.

In this ambivalence, between the desire and the fear, we can also find love hiding the hatred of the same intensity, or even an intense morality and an attachment to cleaning which leads him to develop cleaning or purification rituals. Such rituals became a mere defense of anal-erotic impulses that persist in his unconscious. The pursuit for cleaning hides a dirt that, unconsciously, refers to the idea of the faeces and to his disorganization. Everything that the neurotic can never demonstrate.

In addition, the defense mechanisms present in this neurosis were the subject of Freud study since the clinical case of the Rats Man; but it was in Inhibitions, Symptoms and Anxiety (from 1926) that Freud addresses a chapter to his latest discoveries of mechanisms in this neurosis. Among these, we have the isolation (in which, according to Laplanche, such mechanism consists in isolating athrough in such a way that the remaining connections with other thoughts are interrupted), the annulment (in which an act or action negates the first, using a thought or behavior with an opposite meaning), the displacement (of an aggressive act to an anal act), and the reactive formation, being this an attitude or habit of totally opposite sense to the repressed desire, constituting a reaction against it.

Among all these manifestation, unique in each verbalized history, we cannot forget that in the neurosis class, specifically the obsessive, the society standard and rules are perpetuated, even if for this, it pays high price for its symptom. In a society in which the right rests to the perverse and the duties to the neurotic, the obsessive neurosis survives in the middle of a social holocaust.

However, among its many clinical riches, this neurosis proposes a reflection on the order and law structuring. If this breaks the paternal conflicts, as many psychoanalysts point out, it is from this conflict that results a doubt that organizes the society into an order movement, structuring the rules that govern the good habits. From the fragility of this law is that we can notice the perverse movements, which lead young people and adults to commit barbarous acts. That is why the search for justice is present in the context and in the verbalization of this neurosis.

\section{Psychiatry and Reductions}

Finally, the author would like to return to the beginning of this paper and refute the idea that any psychopathology must be diagnosed by the symptoms. For this purpose, it would be interesting to return to Melanie Klein, the "mother" of British psychoanalysis. Although this psychoanalyst is criticized by the psychoanalysts of the French current, meaning the Lacan followers, such criticisms are supported in a prejudice without justification, once the theory proposed by her opens the doors for the psychotic patients analysis while the Lacan followers, when analyzing Klein work, pored in intellectual criticism of narcissist nature. Quarrels and rivalries aside, it should be mentioned that the Klein brought a new vision to the obsessive symptomatology. 
This psychoanalyst points out that all and any obsessive symptom is in the defense of possible psychotic centers. Thus, the symptom becomes a defense and not the cause of a pathology. And it is from this that it really scares me to observe psychoanalysts adopt a symptomatology posture and persist in errors that culminated in the history tamponment of these patients. This means that not every obsessive symptoms refers, unique and exclusively, to a case of obsessional neurosis. For this reason that we live with a "salad" of diagnostics.

An exit for this "chaos" would be the listening, a listening without prejudices and above any intellectual judgment. A listening marked by the clinical observation and by patient manifestations and associations in the clinical setting. Only this way we can understand the plurality of this neurosis, manifested in the uniqueness of each patient.

\section{Conclusion}

The discussions above show that both neurosis-hysterical and obsessive-put in check the manifestations of desire that interlace with impulse inclinations in our society. While the hysterical neurosis puts in evidence the phallic fixation, moving the hysteria in favor of the phallic bright manifestation and the social recognition in its productions, the obsessional neurosis proposes the freezing logic of thoughts and actions, denoting that these manifestations bring, to the foreground, the characteristics of the self-destructive impulse. These two classes of neurosis are self-complemented: one moved by the impulse of life and the other by the impulse of death; but as in any case there is an exception, for each class of neurosis there is a lack that cannot be completed by plenitude: There comes the symptom, glittering the desire in its manifestations in the pursuit of the eternal completeness that will never be achieved, moving these two classes of neuroses in the tamponment of what cannot be covered, shut up what cannot be silent: the desire and its manifestations in the pursuit of the childish desire eternally lost, but always idealized. Welcome to the neurotic family.

\section{References}

Freud, S. (1894/1996). The defense psychoneurosis. ESB, vol. III. Rio de Janeiro: Imago.

Freud, S. (1900/1996). The dreams interpretation. ESB, vol. V. Rio de Janeiro: Imago.

Freud, S. (1905/1996). Fragment of the analysis of a hysteria case. ESB, vol. VII. Rio de Janeiro: Imago.

Freud, S. (1907/1996). Obsessive acts and religious practices. ESB, vol. IX. Rio de Janeiro: Imago.

Freud, S. (1909/1996). Notes on a case of obsessional neurosis. ESB, vol. X. Rio de Janeiro: Imago.

Freud, S. (1913/1996). The inclination to obsessional neurosis-A contribution to the problem of neurosis. ESB, vol. XII. Rio de Janeiro: Imago.

Freud, S. (1923/1996). The infant genital organization: An interpolation of sexuality theory. ESB, vol. XIX. Rio de Janeiro:Imago. Freud, S. (1925/1996). Some psychic consequences of anatomical distinction between the sexes. ESB, vol. XIX. Rio de Janeiro: Imago.

Freud, S. (1926/1996). Inhibitions, symptoms and anxiety. ESB, vol. XX. Rio de Janeiro: Imago.

Freud, S. (1933/1996). XXXIII Conference-Femininity. ESB, vol. XXII. Rio de Janeiro: Imago.

Hayat, M. (2005). Obsessional Neurosis. In Mijola, Alain de. International Dictionary of Psychoanalysis. Translation of Álvaro Cabral. Rio de Janeiro: Imago.

Laplanche, J., \& Pontalis, J. B. (1967/2001). Psychoanalysis vocabulary. São Paulo: Martins Fontes.

Penteado, Y. (1976). Everything in Pink. Rio de Janeiro: Nova Fronteira.

Roudinesco, E., \& Plon, M. (1998). Psychoanalysis dictionary. Rio de Janeiro: Jorge Zahar Editor. 